\title{
Sjögren Syndrome and Work Disability
}

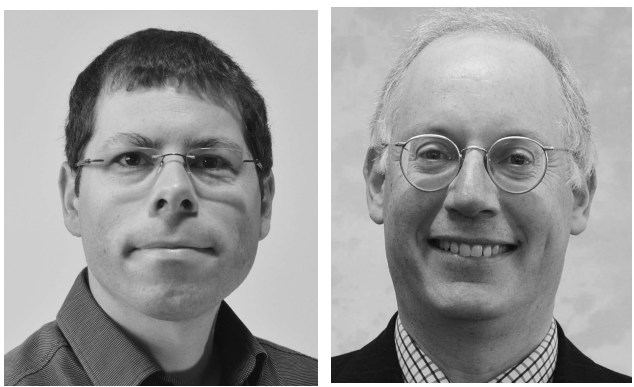

Primary Sjögren syndrome (pSS) is an autoimmune disease characterized by lymphocytic infiltration of salivary and lachrymal glands associated with oral and ocular dryness. It is 9 to 13 times more common in women than men and typically affects women between the ages of 40 and 60 years ${ }^{1}$. Fatigue and pain are common symptoms, reported by $>60 \%$ of patients. They are closely linked with low mood and reduced health-related quality of life in patients with this condition and can be disabling in severity ${ }^{2}$.

As a result, pSS has potential health economic consequences. This is of particular importance as we move into an era of clinical trials for (expensive) biologic agents for pSS manifestations. There are a limited number of published papers about the effect of developing pSS on patients' employment and ability to work and what aspects of the disease may predict work disability ${ }^{3,4,5}$. In this issue of The Journal, Mandl, et al report the results of their study of work disability in newly diagnosed patients with pSS in Skåne County in Sweden 6 . This study prospectively collected clinical data of 51 patients with pSS from the Malmö Sjögren's Syndrome Register and linked these data to employment data from 1 year before to 2 years after the diagnosis of pSS. The employment data came from the Swedish Social Insurance Agency. This was compared to employment data from age-, sex-, and residence-matched controls from the Swedish population register in a 1:4 ratio. At the time of diagnosis, $16 \%$ of patients with pSS were already receiving a disability pension and $10 \%$ were on sick leave. After the diagnosis, the authors showed a steady increase in work disability, initially including sick leave, then latterly including disability pension, rising to $41 \%$ two years after the diagnosis. Patients having pSS and fibromyalgia (FM) showed a significant increase in work disability compared to patients without FM ( $82 \%$ vs $30 \%, \mathrm{p}<0.01), 2$ years after the diagnosis. The relative risk of being work-disabled 2 years after the diagnosis of pSS was more than double that of the general population $(95 \%$ CI
1.34-3.30). A univariate logistic regression analysis showed that the work disability status at pSS diagnosis, the presence of concomitant FM, and the age at pSS diagnosis were associated with work disability (sick leave or disability pension) 2 years after the diagnosis. The European League Against Rheumatism Sjögren's Syndrome Disease Activity Index score $(\mathrm{ESSDAI})^{7}$ and the presence of anti-Ro and/or anti-La antibodies were not associated with work disability.

This well-conducted study adds important new data. Its particular strengths come from the robust and independent nature of the dataset, which includes reliable data from the general population. It is also a longitudinal study and examined newly diagnosed patients rather than individuals with established disease, so it gives an insight into the immediate consequences of developing the condition.

In broad terms the findings of increased work disability in pSS are in keeping with the small number of previous studies $^{3,4,5}$. One clear and consistent message from all of these studies, conducted on different populations, with different experimental designs and different comparators, showed that work disability, including sick leave and disability pension, is significantly higher among patients with pSS than in the general population. Mandl, et al also demonstrate that work disability in pSS is not associated with systemic disease activity (measured with the ESSDAI), and this is also consistent with previously published studies $3,4,5$.

This study uses the same/similar methodology as that used by previous studies from Sweden of patients with new-onset rheumatoid arthritis (RA) ${ }^{8}$ and in systemic sclerosis ${ }^{9}$. By linking clinical patient data to employment data from the Swedish Social Insurance Agency, this provides robust information on work disability. Few countries have high-quality national social security databases like Sweden's. This limits the number of countries for which comparable studies are possible. An alternative approach is therefore to rely on data from self-reported questionnaires. In this situation, as Mandl, et al point out, the Work Produc-

See Work disability in pSS, page 209

Personal non-commercial use only. The Journal of Rheumatology Copyright (c) 2017. All rights reserved. 
tivity and Activity Impairment Questionnaire (WPAI) is emerging as a currently preferred tool in rheumatology to assess both presenteeism and absenteeism in relation to assessing work disability ${ }^{10}$. A number of other validated questionnaires exploring other aspects of work and health economics are also available ${ }^{11}$.

There are still many methodological issues that can lead to differences in the results of health economic studies in rheumatic diseases. Mostly this aspect has been studied in $\mathrm{RA}^{12,13,14}$. In economic analyses, costs can be considered in different categories. Direct healthcare costs such as the actual healthcare expenditure (physician visits, in-patient and day-case admissions, blood tests, imaging, transport costs, etc.) are paid for by the healthcare system. Indirect costs include the productivity loss resulting from sick leave or reduced working hours (often referred to as absenteeism) or early retirement or reduced productivity while at work (often referred to as presenteeism $)^{15}$. There is another level of complexity if data from studies such as that by Mandl, et al are used to calculate the associated indirect costs. The traditional approach, i.e., the "human capital approach" in its simplest iteration, multiplies the time lost from work by the individual's salary and by the time to retirement ${ }^{12}$. In reality, costs associated with work loss are more complex - if the work is covered by a colleague or done by the patient on their return to work, there may be no associated costs. If a person leaves employment to be replaced by an unemployed individual coming into the job market, the only costs may be for temporary cover or recruitment costs - the "friction cost method"16.

Work disability is only a part of the indirect costs (as opposed to direct healthcare costs) that could be underestimated in pSS because most patients are female, who are more likely to be engaged in unpaid and underrecognized activities in familial, social, and cultural domains (e.g., housework, caring for children or parents, or voluntary activities). But this work is of value to society and a cost can be ascribed to it based on the likely costs incurred if someone else was paid to deliver these activities ("intangible losses") ${ }^{17}$. The WPAI includes a question on the ability to do regular daily activities other than work at a job (such as work around the house, shopping, childcare, exercising, studying, etc.). In our previous cross-sectional study ${ }^{4}$ we estimated the annual indirect costs of pSS in female patients in the United Kingdom at between $£ 7677$ and $£ 13,502$ per patient (US\$9553 and US\$16,803), around two-thirds of the value of the indirect costs estimated for RA and significantly higher than costs for the control population $(p<0.001)$. We used the economic component of the Stanford Health Assessment Questionnaire to record patient-reported information on work productivity (absenteeism and presenteeism) and non-work activities $^{18}$. In the same cohort ${ }^{19}$ we estimated the mean annual direct healthcare costs due to pSS in the United Kingdom at $£ 2188$ (US\$2750) per patient [95\% CI
$£ 1831-£ 2546]$, which was not significantly different from patients with RA but higher than for controls [£949, 95\% CI $£ 741-£ 1156$ (US\$1790)]. A univariate analysis showed that disease duration and a low score on the physical function subscale of the Medical Outcomes Study Short Form-36 questionnaire, evaluating health-related quality of life (HRQOL), were associated with increased direct costs.

Recently, Birt, et $a l^{20}$ published a study estimating the direct costs of pSS with data from more than 10,000 patients in the United States using a claims database. The authors found that in the year following the diagnosis of pSS, the annual healthcare costs increased by $40 \%$ to $\$ 20,416$ per person.

The study by Mandl, et al adds to our understanding of work disability in pSS. It reflects the robust data that can be generated by linking clinical data to data from a national social security register. In other countries, to collect data on other aspects of assessing the personal and societal effect of pSS, questionnaire-based data collection offers a potential alternative approach. The other major message of the study by Mandl, et $a l^{6}$ and other similar studies ${ }^{3,4,5}$ is that pSS is associated with significant work disability and that a diagnosis of pSS is a significant burden for both patients and society. Factors that seem more closely predictive of work disability than serological or organ-specific features are fatigue, pain, depression, reduced HRQOL, age, and FM. These are important observations as we start to assess the use of biologic therapies for pSS.
ALEXANDRE DUMUSC, MD, SIMON JONATHAN BOWMAN, PhD, FRCP, University Hospitals Birmingham National Health Service Foundation Trust, Birmingham, UK.

Address correspondence to Prof. S.J. Bowman, Rheumatology Dept., Queen Elizabeth Hospital, Edgbaston, Birmingham B15 2TH, UK. E-mail: simon.bowman@uhb.nhs.uk

\section{REFERENCES}

1. Bowman S, Hamburger J, Price E, Rauz S. Sjögren's syndromeclinical features. In: Watts RA, Conaghan PG, Denton C, Foster H, Isaacs J, Müller-Ladner U, editors. Oxford textbook of rheumatology. Oxford, UK: Oxford University Press; 2013.

2. Segal B, Bowman SJ, Fox PC, Vivino FB, Murukutla N, Brodscholl $\mathrm{J}$, et al. Primary Sjögren's syndrome: health experiences and predictors of health quality among patients in the United States. Health Qual Life Outcomes 2009;7:46.

3. Meijer JM, Meiners PM, Huddleston Slater JJ, Spijkervet FK, Kallenberg CG, Vissink A, et al. Health-related quality of life, employment and disability in patients with Sjogren's syndrome. Rheumatology 2009;48:1077-82.

4. Bowman SJ, St Pierre Y, Sutcliffe N, Isenberg DA, Goldblatt F, Price E, et al. Estimating indirect costs in primary Sjogren's syndrome. J Rheumatol 2010;37:1010-5.

5. Westhoff G, Dörner T, Zink A. Fatigue and depression predict physician visits and work disability in women with primary Sjögren's syndrome: results from a cohort study. Rheumatology 2012;51:262-9. 
6. Mandl T, Jørgensen TS, Skougaard M, Olsson P, Kristensen LE. Work disability in newly diagnosed patients with primary Sjögren's syndrome. J Rheumatol 2017;44:209-15.

7. Seror R, Ravaud P, Bowman SJ, Baron G, Tzioufas A, Theander E, et al. EULAR Sjogren's syndrome disease activity index: development of a consensus systemic disease activity index for primary Sjogren's syndrome. Ann Rheum Dis 2010;69:1103-9.

8. Olofsson T, Petersson IF, Eriksson JK, Englund M, Simard JF, Nilsson J-Å, et al. Predictors of work disability during the first 3 years after diagnosis in a national rheumatoid arthritis inception cohort. Ann Rheum Dis 2014;73:845-53.

9. Sandqvist G, Hesselstrand R, Petersson IF, Kristensen LE. Work disability in early systemic sclerosis: a longitudinal population-based cohort study. J Rheumatol 2015;42:1794-800.

10. Leggett S, van der Zee-Neuen A, Boonen A, Beaton D, Bojinca M, Bosworth A, et al. Content validity of global measures for at-work productivity in patients with rheumatic diseases: an international qualitative study. Rheumatology 2016;55:1364-73.

11. European League Against Rheumatism. Patient-reported outcome measures library. [Internet. Accesssed November 25, 2016.] Available from: http://oml.eular.org/index.cfm

12. Filipovic I, Walker D, Forster F, Curry AS. Quantifying the economic burden of productivity loss in rheumatoid arthritis. Rheumatology 2011;50:1083-90.

13. Verstappen SM. Rheumatoid arthritis and work: The impact of rheumatoid arthritis on absenteeism and presenteeism. Best Pract Res Clin Rheumatol 2015;29:495-511.
14. Van Vilsteren M, Boot CR, Knol DL, van Schaardenburg D, Voskuyl AE, Steenbeek R, et al. Productivity at work and quality of life in patients with rheumatoid arthritis. BMC Musculoskelet Disord 2015;16:107.

15. Braakman-Jansen LM, Taal E, Kuper IH, van de Laar MA. Productivity loss due to absenteeism and presenteeism by different instruments in patients with RA and subjects without RA. Rheumatology 2012;51:354-61.

16. Koopmanschap MA, Rutten FF, van Ineveld BM, van Roijen L. The friction cost method for measuring indirect costs of disease. J Health Econ 1995;14:171-89.

17. Krol M, Brouwer W. Unpaid work in health economic evaluations. Soc Sci Med 2015;144:127-37.

18. Bruce B, Fries JF. The Stanford Health Assessment Questionnaire: a review of its history, issues, progress, and documentation. J Rheumatol 2003;30:167-78.

19. Callaghan R, Prabu A, Allan RB, Clarke AE, Sutcliffe N, Pierre YS, et al. Direct healthcare costs and predictors of costs in patients with primary Sjogren's syndrome. Rheumatology 2007;46:105-11.

20. Birt JA, Tan Y, Mozaffarian N. Sjögren's syndrome: managed care data from a large United States population highlight real-world health care burden and lack of treatment options. Clin Exp Rheumatol 2016 Oct 7 (E-pub ahead of print).

J Rheumatol 2017;44:133-5; doi:10.3899/jrheum.161469 